Introduction The 2015 BTS Emergency Oxygen Audit showed that $4 / 10$ patients on oxygen did not have a valid prescription, $1 / 3$ patients received inappropriate levels of oxygen and almost $1 / 10$ patients were at risk of iatrogenic hypercapnia. Over half of hospitals didn't provide adequate training in oxygen provision and monitoring. Despite significant efforts to improve practice at King's College Hospital, the audit revealed a drop in appropriate prescribing. We conducted a staff survey of attitudes to and knowledge around oxygen prescribing to better understand the barriers.

Methods Hospital based healthcare professionals completed a survey of attitudes to oxygen prescribing as well as a knowledge quiz using Survey Monkey ${ }^{\circledR}$.

Results There were 113 respondents. 67\% were doctors (13\% Foundation Year; 44\% ST1-8; 38\% Consultants). 29\% were nurses, (76\% Band 5/6). Most worked in acute specialties $(28 \%$ A\&E, 15\% anaesthetics, 14\% ICU, 13\% acute medicine). Only $66 \%$ of respondents believed that oxygen should be prescribed on a drug chart. Among doctors, support for oxygen prescribing was high, especially in acute medicine (93\%) and A\&E (86\%). It was lower amongst ICU doctors (50\%). Amongst nurses, support was $41 \%$. Nurses working in medical specialties largely agreed with oxygen prescribing (80\%). Those working in A\&E and ICU did not (33\% and $22 \%$ respectively).

Perceived barriers to prescribing were lack of time, lack of awareness/habit, difficulty accessing computers and a perception that the oxygen prescription would not allow for changes in a patient's condition. Those who believed oxygen did not need to be prescribed felt concerned that prescribing could delay emergency treatment. In the quiz, this group was less able to identify patients at risk of hypercapnic respiratory failure (see figure 1).

Conclusion Oxygen prescribing is still seen by many as a cause of possible delays in emergency treatment. Education of clinical staff, particularly nurses, around risks as well as benefits of emergency oxygen therapy is still needed. Emergency oxygen prescription needs to be as flexible as possible so that prescribing is seen as a means to deliver right care and reduce these risks particularly for those patients at risk of hypercapnic respiratory failure.

\section{M4 LATE ASTHMATIC RESPONSE TO EPOXY RESINS: A CASE REPORT}

${ }^{1}$ E Solano, ${ }^{2}$ B Fitzgerald, ${ }^{2} \mathrm{~J}$ Cannon, ${ }^{2} \mathrm{P}$ Cullinan, ${ }^{2} \mathrm{~J}$ Feary, ${ }^{1}$ Ramon y Cajal. University Hospital, Madrid, Spain; ${ }^{2}$ Royal Brompton and Harefield NHS Foundation Trust, London, UK

\subsection{6/thoraxjnl-2016-209333.446}

Introduction Epoxy resins (ER) systems are used extensively in industry in adhesives, reinforced plastics and surface coatings. ER are converted to the final product by mixing with a "hardener" or curing agent to form a polymer. This process releases fumes which can be respiratory sensitisers and a cause of occupational asthma (OA).

Method A non-atopic, non-smoker, 41 year old was referred with a six-month history of new onset asthma and 10 month history of nasal congestion and sneezing. His wheeze and dyspnoea occurred in the evenings and improved on holidays. He worked as a materials technician developing bonding agents and had started to use a new ER system one year previously. OA to the ER system was suspected and an in-patient specific inhalational challenge (SIC) performed. On day 1, a pre-treatment solution and a solvent (negative controls) were brushed on to a hard surface for 30 minutes. On day 2, the challenge was repeated using the same methods but with the addition of the ER system used at work. Histamine responsiveness 24 hours post challenge, $\mathrm{FEV}_{1}$ and symptoms were all monitored. At baseline $\mathrm{FEV}_{1}$ was $4.3 \mathrm{~L}$ and bronchial response to histamine was normal (PC $2016 \mathrm{mg}$ / $\mathrm{ml}$ ). Blinding was not possible due to the patient's intimate knowledge of the products.

Results Exposure to the control agents induced no symptoms and no change in $\mathrm{FEV}_{1}$ or histamine responsiveness. Six hours after the active challenge $\mathrm{FEV}_{1}$ fell by $16 \%$ and the patient reported chest tightness and wheeze. $22 \mathrm{~h}$ post-challenge $\mathrm{FEV}_{1}$ reached a 
nadir of $2.0 \mathrm{~L}(52 \%$ fall) and bronchodilator therapy was administered (Figure). Histamine responsiveness $24 \mathrm{~h}$ post challenge increased with a PC 20 of $3.3 \mathrm{mg} / \mathrm{ml}$. The active challenge was not repeated.

Conclusion We demonstrated an isolated sustained late asthmatic reaction to the ER system confirming OA. The likely sensitiser was cyclohexylamine (an aliphatic amine hardener) which had a high "Chemical Asthma Hazard Assessment Score" of 0.9283. To ensure patient safety, it is important to be aware of this pattern of response (which is typical of low molecular weight agents). It also explains why the patient did not closely link his symptoms with work. The exact immunological mechanisms are not currently known.

\section{M5 THE CORRELATION BETWEEN SATISFACTION WITH INFORMATION ABOUT MEDICINES AND CLINICAL OUTCOMES IN AN ETHNICALLY DIVERSE DIFFICULT ASTHMA COHORT}

H Dhruve, H Khachi. Bart's Health NHS Trust, London, UK

10.1136/thoraxjnl-2016-209333.447

Introduction It is thought that a common cause of poor asthma control is lack of information about medication and their use. This study aims to investigate the influence of satisfaction with information about medicines and its associated clinical outcomes in patients in a difficult asthma cohort.

Methodology Ethics approval was granted. All patients attending a difficult asthma clinic in a large tertiary centre were invited to participate. The Satisfaction with Information about Medicines Scale (SIMS) questionnaire was used. ${ }^{1}$ This validated 17 item questionnaire, explores various aspects of medication information with preventer inhalers and the associated patient satisfaction with this. Demographic and adherence information from the GP were also collected. SPSS version 22.0 was used to analyse the data.

Results The table shows that patients from non-Caucasian backgrounds had statistically significantly lower reported satisfaction with information about medicines. There was also a statistically significant correlation between low satisfaction with information and increased salbutamol use and rates of asthma exacerbations.

Discussion This study shows the importance of ethnicity to the level of satisfaction with information about medicines. Language barriers, lack of understanding or health beliefs could be contributing factors. Our study found no statistical significance found between GP prescription refill rates (adherence) and associated exacerbations and salbutamol use. However, it is worth noting that our study did not investigate whether patients who picked up their preventer inhalers were indeed using them as intended by their clinician, nor did it assess inhaler technique.

Conclusion We have shown that using a validated questionnaire can help identify patients who are at risk of having a lower satisfaction with their medicines and in turn a greater likelihood of having poorer clinical outcomes. Eliciting satisfaction with information about medication can help tailor interventions to support clinical outcomes in patients from ethnic minorities.

\section{REFERENCE}

1 Horne R, Hankins $M$, et al. The Satisfaction with Information about Medicines Scale (SIMS): a new measurement tool for audit and research. Qual Health Care 2001;10(3):135-140
Abstract M5 Table 1

\begin{tabular}{|c|c|}
\hline & $\begin{array}{l}\text { Satisfaction with information about } \\
\text { medicines Scale (SIMS) - likelihood to be } \\
\text { satisfied with preventer inhaler medication }\end{array}$ \\
\hline $\begin{array}{l}\text { Gender } \\
\text { Female }(n=49) \\
\text { Male }(n=26)\end{array}$ & No significant difference between genders found \\
\hline $\begin{array}{l}\text { Age } \\
\begin{array}{l}18-30(n=2) \\
31-50(n=35) \\
51-70(n=31) \\
70+(n=7)\end{array}\end{array}$ & No significant difference between ages found \\
\hline $\begin{array}{l}\text { Ethnicity } \\
\text { - White Caucasian }(n=46) \\
\text { - Ethnic Backgrounds }(n=29) \\
\text { Asian }(n=21) \\
\text { Black Afro-Caribbean }(n=6) \\
\text { European }(n=2)\end{array}$ & $\begin{array}{l}\text { Satisfied }(P<0.01) \\
\text { Not satisfied }(P<0.01)\end{array}$ \\
\hline $\begin{array}{l}\geq 80 \% \text { Adherence to inhaled } \\
\text { corticosteroids (ICS) as per GP refill } \\
\text { information }\end{array}$ & $\begin{array}{l}\text { No significant correlation between satisfaction } \\
\text { and adherence found }\end{array}$ \\
\hline Salbutamol use/day & $\begin{array}{l}\text { Increased salbutamol use when not satisfied } \\
(P<0.05)\end{array}$ \\
\hline Exacerbations per year & $\begin{array}{l}\text { Increased rate of exacerbations when not } \\
\text { satisfied }(P<0.05)\end{array}$ \\
\hline
\end{tabular}

\section{M6 IMPROVING FOLLOW-UP IN PATIENTS ATTENDING AND DISCHARGED FROM ACCIDENT AND EMERGENCY WITH ASTHMA EXACERBATIONS}

WJ Newman, 0 Lamont. Forth Valley Health Board, Larbert, UK

\subsection{6/thoraxjnl-2016-209333.448}

Introduction The Respiratory and Accident and Emergency (A\&E) departments in Forth Valley audited asthma care in the emergency department over the past years. Shortcomings in a number of areas have been identified and quality improvement measures undertaken.

One area was the failure to organise follow-up for patients following attendance at A\&E, (24\% in 2009, $47 \%$ in 2012). As a result a new system was introduced.

Methods Forth Valley Health Board serves a population of 310,000 and has one acute hospital with 860 beds. The Respiratory Service comprises of 6 Consultants and 5.5 Respiratory Nurses. There are specialist asthma clinics run by the physicians/ nurses. Patients with an asthma exacerbation discharged from the $A \& E$ department are identified by interrogating the A\&E patient management system daily and clinical and contact details obtained. The Respiratory nurses contact any patient to obtain further information (standardised questionnaire) and make a management plan with the patient. Their case is then discussed with the on-call Respiratory physician and further recommendations instituted.

Results 88 cases ( 27 (30\%) male, 61 (70\%) female) were identified as having attended with an exacerbation of their asthma and discharged from A\&E during 2015. Median age 36 (range 17$78), 46(58 \%)$ presented at weekends or outwith working hours (0800-1800), 70 (80\%) were discharged home with oral steroids.

Of the 88 patients one had no telephone/one lived outside the UK. $26(30 \%)$ patients did not reply and the GP practice was 